BUILDING TECHNOLOGICAL CAPABILITY

FOR SELF-RELIANCE

Kirit s. Parikh

August 1980

PP-80-7

Professional Papers do not report on work of the International Institute for Applied Systems Analysis, but are produced and distributed by the Institute as an aid to staff members in furthering their professional activities. Views or opinions expressed are those of the author(s) and should not be interpreted as representing the view of either the Institute or its National Member organizations.

INTERNATIONAL INSTITUTE FOR APPLIED SYSTEMS ANALYSIS A-2361 Laxenburg, Austria 
' 
PREFACE

This is a slightly revised yersion of the inyited paper presented at the "SCRIER-NCAER Workshop on Technology", held in New Delhi on April 11 and 12, 1980.

The seminar was sponsored jointly by SCRIER--Steering Comittee for Research in International Economic Relations--and NCAER--National Council of Applied Economic Research. 



\section{BUILDING TECHNOLOGICAL CAPABILITY FOR}

SELF-RELIANCE

Kirit S. Parikh

In spite of a clear national commitment, the strong political will of the two major prime-ministers, the input of a huge amount of resources over the past three decades, and a cultural background where the "brahminical achievements" of $R$ and $D$ are highly valued, we still have a long way to go before a scientific attitude and approach are instilled into our society. This is obvious when one considers the national reaction to the total eclipse of the sun on February 16, 1980.

Delhi was a ghost-town and I am sure that the other cities in the country were also so. Not only did people not look at the eclipse but they also refused to stir out of their homes. Some even drew the curtains lest the "evil" rays of the eclipsed sun come and blind them. The fact that an eclipse is an occurence which is understood by science, and that watching it could be scientifically instructive to all, particularly children, was not recognized. Instead of taking this opportunity to instil enthusiasm, excitement and a wonder of nature in their children, they were scared, frightened and made superstitious.

Moreover, the Director of the country's premier medical research institute was gleeful and triumphant at the psychosis he was able to generate with the help of our equally unscientific mass media. The dangers of watching the eclipse are easily explainable and the necessary precautions against them not hard to take. The masses in İndia are still not considered educable and so not only was an opportunity to spread some enlightment lost, but also superstition was bred. An equally depressing fact was that people in general did not ask why it was dangerous to look at the sun.

Why, one must ask, are we so unscientific? What have been the limitations of our efforts to build $S \& T$ capability? What have been our achievements? Have we spent resources wisely? What should we do to improve the $S \& T$ climate in our country? It is these issues that this paper is addressed to. 
Table 1. Growth of education.

\begin{tabular}{llllll}
\hline & $\begin{array}{l}\text { Expendi- } \\
\text { ture on } \\
\text { educa- } \\
\text { tion }\end{array}$ & $\begin{array}{l}\text { No. of } \\
\text { univer- } \\
\text { sities* }\end{array}$ & IIT's & $\begin{array}{l}\text { No. of Insti- } \\
\text { with post- } \\
\text { graduate } \\
\text { courses }\end{array}$ & $\begin{array}{l}\text { No. of medi- } \\
\text { medical } \\
\text { colleges }\end{array}$ \\
\hline (Rs.crores) & & & & \\
$1947-48$ & 55 & 20 & - & 5 & 22 \\
$1950-51$ & 114 & 30 & 1 & 10 & 30 \\
$1960-61$ & 344 & 59 & 5 & 33 & 71 \\
$1970-71$ & 1118 & 95 & 5 & 77 & 99 \\
$1975-76$ & 2107 & 111 & 5 & n.a. & 109 \\
\hline
\end{tabular}

* Including institutes deemed as universities.

Building Up the Scientific Manpower

India's achievements in developing a large and diversified $S \& T$ system are impressive. The growth of educational facilities, output and stock of scientific and technological manpower are shown in tables 1 to 3 .

Compared to other developing countries, India's quantatitive achievements in this area are significant. However, these figures alone do not give any idea of the quality of the training or the problem solving ability of the scientific personnel trained. Unfortunately it is difficult to measure the quality of education and no data exist on the subject. One then has to proceed with casual empiricism.

The Quality of Technical Education

The fact that apart from creating five IIT's and some minor curriculum revisions in technical educations, no new innovative approaches to teaching and training have been tried, implies that probably the quality of technical education has not improved much over the past twenty-five years. As one who went through undergraduate engineering education twenty-five years ago in perhaps a fairly representative college, I can say that technical education then did not give one confidence or even a feeling that one could solve problems in a logical scientific way. The theory that was taught did not seem related to any practical problems. It was a frequent complaint of examinees that the paper was difficult and unfair as it asked questions of a practical nature.

The fact that no new innovations have been made to remedy this long standing deficiency of training in India, would also imply that no new directions are given to course content to make 


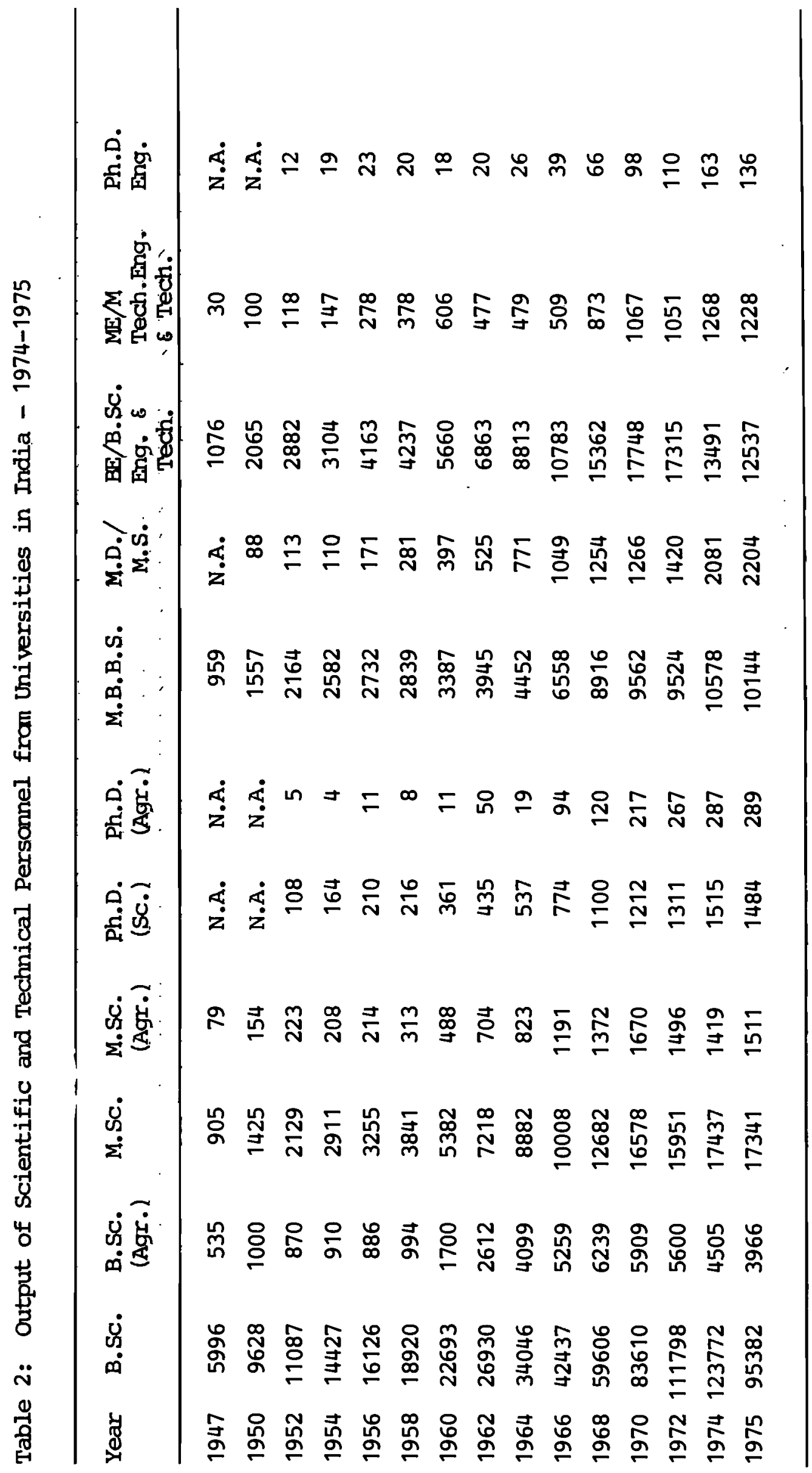




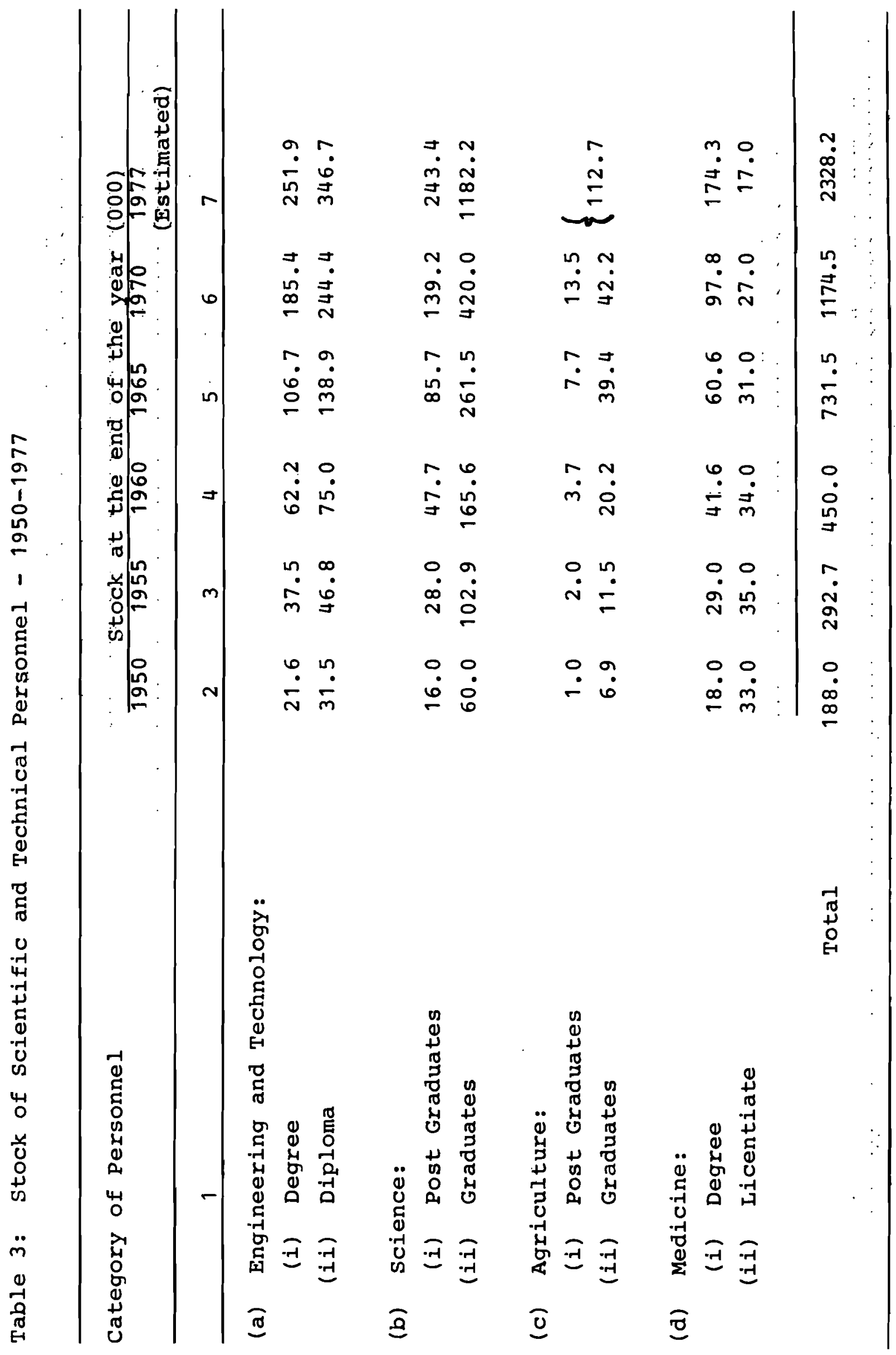


it more relevant for a developing country. Engineers trained to use thumbrules who are not even aware of how the thumbrules are derived, are not likely to be aware that these thumbrules should change with relative prices of inputs and/or factors. This also means that they are not aware of trade-offs. That one can build a house without plaster, with jalis instead of windows, with cement floors instead of terazzo tiles and provide one more room by the savings affected would be understood but not appreciated by our engineers. Consequently they would never offer such a choice to a user, who may well opt for a bigger but "poorly" finished house. But apart from the fact that our engineers do not fully appreciate such trade-offs, they may also have a value system that is inappropriate to the country. When suggested that one could build a cheaper house by sacrificing finishes which are functionally not necessary, they react that this is "langoti (loin-cloth) architecture."

Thus our technical training seems to produce engineers who:

(a) lack problem solving ability and confidence;

(b) are generally unaware of trade-offs in design and technical solutions; and

(c) have inadequate appreciation of what is relevant and appropriate technology for the country.

These deficiencies are such that they can be removed by appropriate training, by changing the course content and by introducing more efficient training methods.

Effective Use of Trained Professionals

The potential for technological self-reliance that a country builds up through training and education of scientists and technologists can be realized only if they are effectively employed in RED and consulting and design organizations. How effectively have we done this?

The RED Sector

The effectiveness of RED is difficult to measure. Yet applications of RED should be certainly an important item in it.

In table 4 are shown the number of patents sealed in the name of Indians, income of NRDC from Royalty and Premia as also the value of goods produced from processes licensed by NRDC (National Research and Development Corporation). The number of patents may be an inadequate measure as patent consciousness is not high in India, yet it does provide some idea about the success of RED. 
Table 4. Some Indicators of RED Applications.

\begin{tabular}{cccc}
\hline & $\begin{array}{l}\text { No. of patents } \\
\text { sealed in the } \\
\text { name of Indians }\end{array}$ & $\begin{array}{l}\text { Income from } \\
\text { Royalty } \varepsilon \\
\text { Premia }\end{array}$ & $\begin{array}{l}\text { Value of goods } \\
\text { produced by processes } \\
\text { licensed by NRDC }\end{array}$ \\
\hline & & (Rs.crores) & (Rs.crores) \\
& & & .29 \\
$1960-61$ & 426 & & 5.00 \\
1968 & 645 & .22 & 4.80 \\
1969 & 596 & .26 & 6.00 \\
1970 & 629 & .37 & 8.75 \\
1971 & 278 & .32 & 10.00 \\
$1972-73$ & 358 & .38 & 12.00 \\
$1973-74$ & 737 & .50 & 18.00 \\
1975 & 426 & .67 & 23.00 \\
1976 & 928 & & 40.00 (estimated) \\
1977 & & & \\
\hline
\end{tabular}

These returns have to be compared with the expenditures on RED. These are shown in table 5 .

The NRDC royalty can be considered to be based at least on the CSIR laboratories which have over the years, got between 16 to 25 percent of the central sector outlay on RED. The NRDC royalty is extremely meagre compared to this outlay. So also is the value of product based on these processes. It is not clear from the data whether the value of product is "value added" or just "value of product"--I suspect it is just value of product, . whereas "value added" should be considered as a proper measure of benefit of RED.

Similarly the large amount of resources, between 25\% to $40 \%$ of the central sector outlay over the years poured into $R \dot{ }$ D in the Department of Atomic Energy (DAE), has yet to give any tangible economic return to the country.

One may argue that there is an " $S$ "in CSIR which is a Council Eor nat only Industrial Research but also for Scientific Research, and that both $\mathrm{DAE}$ and CSIR have been instrumental in setting up the impressive infrastructure for SET in the country. Yet even if one were to consider half of the expenditure fully as expenditure for "scientific" rather than for "industrial" research, the benefits still seem meagre compared to the costs. And 30 years is a long enough time for results to show even for infrastructural development. 
Table 5: Expenditures on RED (Rs.crores)

\begin{tabular}{|c|c|c|c|c|}
\hline Year & $\begin{array}{l}\text { Central } \\
\text { Sector }\end{array}$ & $\begin{array}{l}\text { State } \\
\text { Sector }\end{array}$ & $\begin{array}{l}\text { Private } \\
\text { Sector }\end{array}$ & Total \\
\hline $1948-49$ & 1.1 & n.a. & n.a. & n.a. \\
\hline $1950-51$ & 4.68 & n.a. & n.a. & n.a. \\
\hline $1955-56$ & 12.14 & n.a. & n.a. & n.a. \\
\hline $1958-59$ & 21.78 & 1.0 & 0.15 & 22.93 \\
\hline $1965-66$ & 62.45 & 3.51 & 2.43 & 68.39 \\
\hline $1968-69$ & 85.72 & 11.99 & 9.85 & 107.56 \\
\hline $1969-70$ & 91.59 & 12.22 & 12.81 & 116.62 \\
\hline $1970-71$ & 112.47 & 12.58 & 14.59 & 139.64 \\
\hline $1971-72$ & 125.93 & 9.53 & 16.18 & 151.64 \\
\hline $1972-73$ & 149.67 & 22.11 & 22.89 & 194.67 \\
\hline $1973-74$ & 161.53 & 24.13 & 30.35 & 216.01 \\
\hline $1974-75$ & 231.14 & 24.00 & 36.46 & 291.60 \\
\hline $1975-76$ & 287.61 & 26.73 & 42.35 & 356.69 \\
\hline $1976-77$ & 321.73 & 31.02 & 49.50 & 402.25 \\
\hline
\end{tabular}


It is clear from table 4 that the bulk of RED expenditure is under the central sector. The organizations involved in RED in the central sector can be grouped in two broad classes. The discipline or area oriented laboratories such as the CSIR laboratories and the task oriented organizations such as DAE, ISRO, ICAR etc.

Another major RED resources absorbing department is the Indian Council for Agricultural Research. The contributions of agricultural research in promoting the green revolution in agriculture have been significant.

In agricultural research, soil and climate specific varieties have to be developed. Thus similar researches have to be carried out in many agricultural stations around the country. Moreover, a number of agricultural universities are also actively involved in research. Thus quite a lot of healthy competition exists among agricultural researchers, and this may not be an insignificant factor in explaining the success of such research in the country.

Unfortunately, apart from agricultural research, such competition does not seem to exist in other areas. The CSIR laboratories (which are usually only one per academic discipline) tend to be very zealous of their position and claim pre-eminence in the area. This tends to discourage others from working in that area. The monopolistic position is maintained through the unfair competition that a public sector organization offers to others as it has no compulsion to earn its own living. Moreover, in such monopolistic laboratories with their characteristic governmental structure and lack of specific task orientation, dissent is discouraged and so is creativity. The failure of CSIR laboratories to perform better than they have even on their own terms may be explained by this lack of competition. What is needed is the break up of national laboratories into a number of independent parallel laboratories.

Another, and perhaps more important, factor in the failure of the CSIR laboratories to produce appropriate RED, is lack of proper perspective on what is socially relevant and appropriate research. Pre-investigation economic benefit-cost analysis of research could be very useful in eliminating much research on irrelevant tasks.

The poor performance of the task oriented organizations can be explained on the basis of lack of competition and bureaucratic administrative structures. The need to create competition is as great as the efforts of some of these departments to prevent competition. The efforts of BHEL some years ago to set up a nuclear power plant design and construction organization was successfully blocked by the DAE which has so far completed only one power plant (apart from the plant built by GE on a turnkey basis). Such attempts at keeping out competition are not confined to the public sector only, but the public sector is usually more successful in its attempts than the private sector. 
Consulting and Design Organizations

The development of consulting firms is also hampered by the inappropriate growth of large public sector design organizations. Many of these were created to design large complex projects for which there was no competent body available in the country. Some have grown quite large over the years and have also successfully carried out a number of projects. Yet this has happened not without costs. When a large public sector firm exists, it usually secures all the government and other public sector organization contracts (procedurally it is easier to award a contract to a public sector firm even when its costs are high). Thus no private organization can flourish in the same area. This lack of competition and cost-plus contracts soon lead to staleness and mediocrity. It is also typical that such firms grow large rapidly when they are trying to execute a project. But should the next project be of a different nature, these firms are faced with the wrong kind of staff and cannot dismiss existing staff members who then become idle. Idleness results in obsolescence and demoralization. As there are no other firms in the country engaged in similar work in the area, it is not easy for them to find alternative employment in the country. They either vegetate or emigrate.

What is needed is the development of vigorous and active private competitive consulting and design engineering firms. The growth of such firms can be stimulated by the practice of subcontracting which must be encouraged. Public sector design firms should be small, extremely competent project management firms capable of parceling out the task to many small firms as sub-tasks. This would save the public sector firms from getting stuck with idle men and would promote a healthy growth of private consulting firms. It would also give people the option to seek alternative jobs. Dissent, integrity and creativity can then flourish.

Thus decentralization and competition are required if $R E D$ and consulting and design organizations are to be revitalized.

The Requirements for Self-Reliance: Not just know How and know Why, but also know which

Technological self-reliance requires not only "know-how" (the knowledge on how to design or execute a technological task) and "know-why" (why a particular technological process or piece of equipment is designed the way it is), but also "know-which" (which of the many technological alternatives should be selected). Such analytical self-reliance is important if the country is to avoid the pursuit of irrelevant and/or obselete technologies, or being tricked into accepting these, and the wasting of efforts, resources and time in the acquisition of know-how and know-why concerning them.

Have we giver adequate attention to know-which? Are the strategy and tactics followed by us such that they promote 
question on the relevance and appropriateness of the technologies being pursued from within the scientific community itself?

This is perhaps an area in which we have not made any systematic effort. And much of the effort wasted in the field of RED may result from lack of that effort. Our first task is to recognize the importance of systems studies for the evaluation of alternative technologies and the importance of systematic quantitative approaches to SET strategy planning. 